\begin{tabular}{ccc}
\hline \\
ISSN:2639-6009)
\end{tabular}

\title{
MATERNAL MORTALITY IN A MATERNITY WARD AT A REGIONAL HOSPITAL CENTER IN SOUTERN SENEGAL
}

\author{
Biaye B, Diallo M, Guéye M, Gassama O, Niassy Diallo AC, Toure Y, Cisse M, Wade M, Ndour \\ SB, Sarr PM, Diouf AA, Diouf A, Moreau JC.
}

Aristide Le Dantec hospital in Dakar, Senegal

\begin{abstract}
Objectives: •to determine the maternal mortality ratio at the Kolda Regional Hospital; •to describe the socio-demographic characteristics of the deceased patients; •to clarify the causes of maternal mortality and to identify the associated risk factors.

Materials and method: This was a prospective, descriptive and analytical study conducted between January 1st, 2012 and December 31st, 2016 at the Kolda Regional Hospital Center. We collected data from maternity records, resuscitation records, anesthesia records and the operating protocol register.

Results: During this study period, we recorded 120 maternal deaths out of 4116 living births, a maternal mortality ratio of 2915.4 per 100,000 living births. The average age of our patients was 27 years old. The average parity was 4 deliveries and multiparas accounted for half of the patients. In our series, $84 \%$ of patients were evacuated; high blood pressure $(35.8 \%)$ and obstructed labor (18.8\%) were the most common reasons for evacuation. More than half of the deaths $(52.5 \%)$ occurred in the postpartum and $32.5 \%$ in the 3rd quarter. More than half of the deaths occurred within the first 24 hours after of admission (52\%). Just over a third of patients $(39 \%)$ had delivered by caesarean section and we had $58.8 \%$ of perinatal deaths. The conclusions of the audit were a delay in consultation (57\%) followed by a delay in evacuation (28\%) and a delay in the management of patients (25\%).

Conclusion: The multiple factors influencing the high maternal mortality rate in this region of Senegal can be attributed to the community, the medical team, and / or the health system. Strategic interventions to reduce this mortality rate should be based on community education on safe motherhood, on the improvement of the level of education, on communication systems and better transportation, on access to quality reproductive health services and availability of emergency obstetric care.

Keywords: Audit, maternal mortality, Kolda.

*Correspondence to Author:

Biaye B

Aristide Le Dantec hospital in Dakar, Senegal

How to cite this article:

Biaye B, Diallo M, Guéye M, Gassama O, Niassy Diallo AC, Toure $Y$, Cisse M, Wade M, Ndour SB, Sarr PM, Diouf AA, Diouf A, Moreau JC.MATERNAL MORTALITY IN A MATERNITY WARD AT A REGIONAL HOSPITAL CENTER IN SOUTERN SENEGAL. International Research Journal of Obstetrics and Gynecology, 2019, $2: 10$

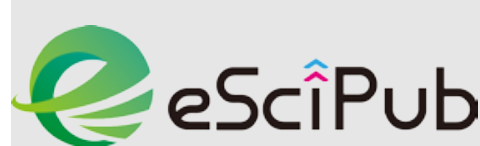
eSciPub LLC, Houston, TX USA. Website: https://escipub.com/
\end{abstract}




\section{Introduction}

Maternal mortality remains a major public health problem in the world. It is of considerable importance in many developing countries and is an indicator of the quality of care in obstetrics [1]. According to the World Health Organization (WHO), about 830 women die every day from preventable causes related to pregnancy and childbirth. $99 \%$ of all maternal deaths occur in developing countries, $62 \%$ of which are in subSaharan Africa. Maternal mortality is higher in rural areas and in the poorest communities. The risk of complications and deaths due to pregnancy is higher in young adolescent girls than in older women [2]. The assistance of qualified personnel before, during and after delivery can save the lives of women and newborns. Between 2016 and 2030, as part of the Sustainable Development Goals, the goal is to reduce the global maternal mortality rate to below 70 per 100,000 live births $[1,2]$. In Senegal, the maternal mortality ratio has fallen significantly, but remains high. In fact, it went from 510 to 315 deaths per 100,000 living births between 1992 and 2015. Every day, 4 women lose their lives by giving birth. There is an excess mortality of teenage mothers with 629 deaths per 100,000 living births. Kolda region is one of the most affected by this scourge. In fact, it has a maternal mortality rate of 417.6 per 100,000 living births [3].

Reducing maternal mortality is therefore a priority goal in our developing countries. To accompany this process and understand the reasons for this high maternal mortality rate in Kolda, we proposed to carry out this study whose specific objectives were as follows:

- to determine the maternal mortality ratio at the Kolda Regional Hospital;

- to describe the socio-demographic characteristics of the deceased patients;

- to clarify the causes of maternal mortality and to identify the associated risk factors.

\section{Patients and method}

This was a prospective, descriptive and analytical study conducted between January 1st, 2012 and December 31st, 2016 at the Kolda Regional Hospital Center. We included in our study all pregnant women who were monitored or who gave birth in this structure and who died during pregnancy, childbirth or the 42 days that followed. In this study we excluded pregnant women or women who delivered and whose death took place in a structure other than ours or at home.

We collected data from birth records, from resuscitation records, from anesthesia records and from the operating record book.

We have studied the following parameters:

- the socio-demographic characteristics of the patients: age, gestation, parity;

- the data of the delivery: the mode of delivery, the place of birth, the mode of admission, the place of admission;

- the observed complications, the place of death and the cause of death.

We entered data using the Epi Info6 software. We also did the exploitation and analysis using the same software and SPSS. For bivariate analysis, we used chi2 tests according to their applicability and the significance of the association was verified using the chi2 test; and the threshold value for the $p$ was 0.05 .

\section{Results}

\section{Descriptive results}

\section{Maternal Mortality Ratio}

During the five years, we recorded 120 maternal deaths out of 4,116 live births, a maternal mortality ratio of 2915.4 per 100,000 living births (Table 1).

\section{Sociodemographic characteristics}

\section{Age}

In our series, the average age of our patients was 27 years with extremes of 16 and 40 years. The most representative age group was 25 to 34 years $(60 \%)$ (Figure 1$)$. 
In our series, 118 patients were married, that is Clinical data $99 \%$.

\section{Antecedents}

\section{Gesture and parity}

The average pregnancy was 6 pregnancies with extremes of 1 and 13 pregnancies. Multigestes accounted for almost half of the patients $(47.1 \%)$.

The average parity was 4 deliveries with extremes of 0 and 9 deliveries. Multiparas accounted for half of the patients (50\%).
In this study we found four cases of women in labor with high blood pressure (3.3\%), two cases of diabetes (1.6\%) and 2 cases of HIV infections $(1.6 \%)$ and the same rate was found in our patients with sickle cell.

Eleven patients had a scarred uterus (9.2\%) and 06 had a history of abortion (5\%) (Table 2).

Table 1: Maternal Mortality Ratio at the Kolda Regional Hospital Center between January 1, 2012 and December 31, 2016 ( $N=120)$.

\begin{tabular}{lllll}
\hline Year & Number of deliveries & $\begin{array}{l}\text { Number of living } \\
\text { births }\end{array}$ & $\begin{array}{l}\text { Number } \\
\text { maternal deaths }\end{array}$ & $\begin{array}{l}\text { Maternal motality } \\
\text { ratio / 100000 NV }\end{array}$ \\
\hline $\mathbf{2 0 1 2}$ & 964 & 744 & 23 & 3091.4 \\
$\mathbf{2 0 1 3}$ & 885 & 707 & 22 & 3111.7 \\
$\mathbf{2 0 1 4}$ & 975 & 746 & 23 & 3083.1 \\
$\mathbf{2 0 1 5}$ & 1124 & 942 & 25 & 2653.9 \\
$\mathbf{2 0 1 6}$ & 1266 & 977 & 27 & 2763.5 \\
Total & 5214 & 4116 & 120 & 2915.4 \\
\hline
\end{tabular}

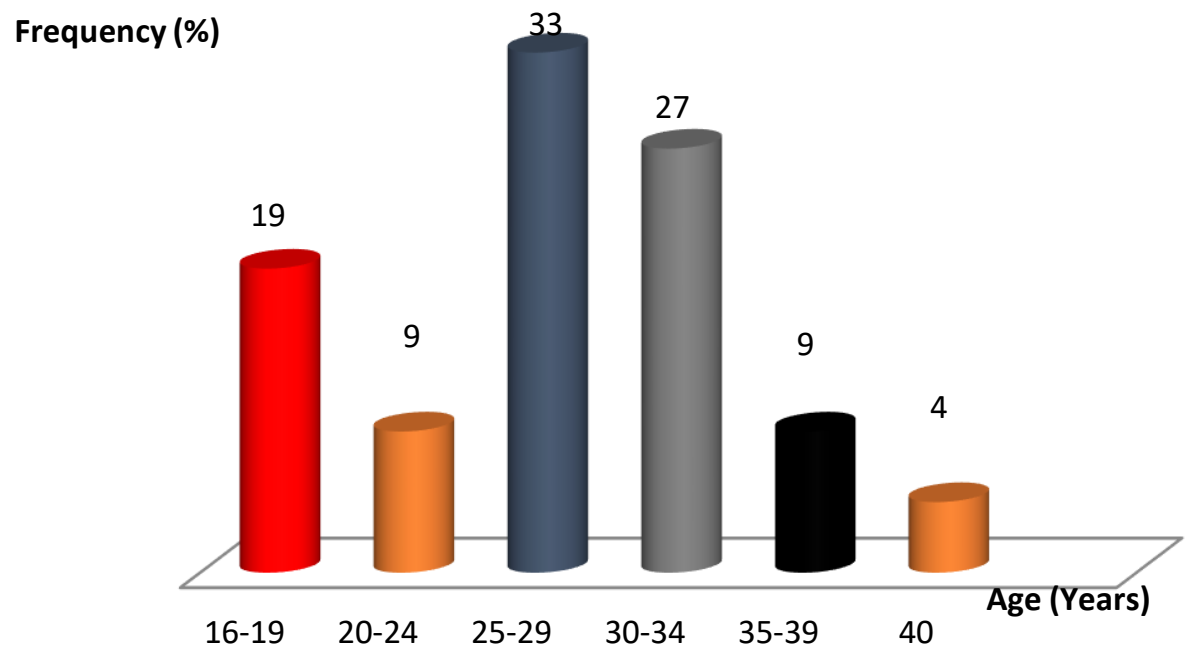

Figure 1: Age distribution $(n=120)$.

Table 2: Breakdown by History

\begin{tabular}{lll}
\hline Health history & Number & Frequency \\
\hline health history & & \\
High blood pressure & 04 & $3.3 \%$ \\
Diabetes & 02 & $1.6 \%$ \\
Sickle cell & 02 & $1.6 \%$ \\
Obstetric history & & \\
Scarred uterus & 11 & $9.2 \%$ \\
Abortion & 06 & $5 \%$ \\
\hline
\end{tabular}




\section{Pregnancy history}

In our series, only 6 patients $(8.8 \%)$ had received at least prenatal consultations, while $28(23.5 \%)$

had no follow-up during pregnancy.

Table 3: Distribution according to pathologies encountered during pregnancy

\begin{tabular}{lll}
\hline Diagnosed Pathologies during pregnancy & Number & frequency $(\%)$ \\
\hline Anemia & 61 & 50.5 \\
High blood pressure & 49 & 40.5 \\
Scarred uterus & 11 & 13.2 \\
HRP & 4 & 3.3 \\
Diabetes & 2 & 1.6 \\
HIV infections & 2 & 1.6 \\
Sickle cell & 2 & 1.6 \\
\hline
\end{tabular}

\section{Mode of admission and origin of patients}

In our series, $84 \%$ of patients were evacuated compared to only $16 \%$ who came by
All of our patients had at least one pathology and anemia was found in half of the patients (Table 3).

Table 4: Distribution according to the origin of evacuated patients

\begin{tabular}{lll}
\hline Origin & Number & Frequency (\%) \\
\hline Kolda Region & & \\
District of Kolda & 64 & 63.2 \\
District of Velingara & 14 & 14 \\
District of Medina Yoro Foulah & 4 & 4 \\
Sedhiou Region & $\mathbf{1 9}$ & $\mathbf{1 8 . 8}$ \\
Total & $\mathbf{1 0 1}$ & $\mathbf{1 0 0}$ \\
\hline
\end{tabular}

\section{Reasons and conditions of evacuation}

The most common reasons for evacuation were high blood pressure (35.8\%) and obstructed labor (18.8\%) (Table 5). themselves. Among the evacuated patients, 64 $(63.2 \%)$ were from the Kolda District and 19 $(18.8 \%)$ were from the Sedhiou area (Table 4). 


\section{Clinical examination at admission}

More than half of the patients $(66 \%)$ had a clear conscience and 96 patients or $80 \%$ had a stable hemodynamic state. More than half of the deaths $(52.5 \%)$ occurred in the postpartum and $32.5 \%$ in the 3rd quarter (Table 6).

Table 6: Distribution according to the Term of Pregnancy

\begin{tabular}{lll}
\hline Term of pregnancy & Number & Frequency (\%) \\
\hline Second trimester & 18 & 15 \\
Third trimester & 39 & 32.5 \\
Post-partum & 63 & 52.5 \\
Total & $\mathbf{1 2 0}$ & $\mathbf{1 0 0}$ \\
\hline
\end{tabular}

\section{Place and method of delivery}

Half of the patients had given birth at the Kolda Regional Hospital (Table 7).

Just over one third of patients (39\%) had delivered by caesarean section. Only $22 \%$ of them gave birth vaginally. In addition, we recorded 10 uterine rupture $(8 \%)$ which required a laparotomy.

\section{Time between admission and maternal death}

The delay between admission and maternal death ranged from 5 minutes to 19 days. More than half of the deaths occurred within the first 24 hours after admission (52\%), 27\% between 24 and 48 hours and $21 \%$ beyond 48 hours (Table 8).

Table 7: Distribution according to place of delivery

\begin{tabular}{lll}
\hline Place of delivery & Number & Frequency (\%) \\
\hline Kolda Regional Hospital & 60 & 50 \\
At Home & 13 & 10.8 \\
Health Post & 5 & 4.2 \\
Kolda health centrer & 5 & 4.2 \\
Pregnancy in progress & 37 & 30.8 \\
Total & $\mathbf{1 2 0}$ & $\mathbf{1 0 0}$ \\
\hline
\end{tabular}

Table 8: Distribution by Time between Admission and Time of Death

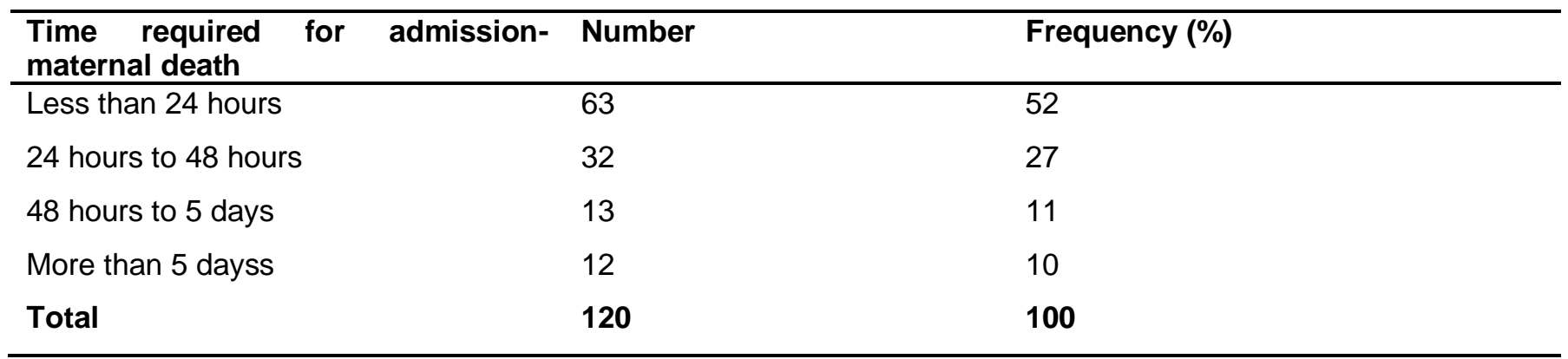

\section{Causes of maternal deaths}

More than two-thirds (67.5\%) of maternal deaths were due to direct obstetric causes. Hemorrhage of delivery and syndromes and vascular-renal syndromes accounted for almost half of the cases (Table 9). 
Table 9: Distribution according to the cause of death

\begin{tabular}{lll}
\hline Pathologies maternels & Effectif & Frequency (\%) \\
\cline { 1 - 2 } Causes directes & 30 & 25 \\
Hemorrhage of the delivery & 29 & 24.2 \\
Preeclampsia/Eclampsia & 12 & 10 \\
Retroplacental hematoma & 10 & 8.3 \\
Uterine rupture & & \\
Indirect Causes & 12 & 10 \\
Postpartum endometritis & 12 & 10 \\
Severe anemia & 7 & 5.8 \\
Severe malaria & 3 & 2.5 \\
HIV/IADS Infection & 5 & 4.2 \\
Others & $\mathbf{1 2 0}$ & $\mathbf{1 0 0}$ \\
Total & & \\
\hline
\end{tabular}

\section{Fetal prognosis}

In our series, we recorded $58.8 \%$ of perinatal deaths, including $49.5 \%$ of fresh born deaths and $9.3 \%$ of macerated stillbirths.

\section{Medical assistance}

All the patients admitted to the structure had received immediate treatment.

\section{Medical treatment}

Blood transfusion (38.5\%), and medical management of hypertensive conditions and their complications were the most commonly performed treatments

\section{Obstetric-surgical treatment}

More than a third of the patients had benefited from cesarean section (39.2\%), laparotomy for uterine rupture was performed in 10 patients or $8 \%$ of cases.

\section{Maternal Death Audit Committee Findings}

Of the 120 maternal deaths recorded in five years, only 41 cases were audited (34\%). The audit revealed that $70 \%$ of deaths were preventable concluding that there was a delay in the consultation (57\%) followed by a delay in the evacuation procedures $(28 \%)$ and a delay in the medical management of cases (25\%).

\section{Analytical results}

\section{Risk Factors for Maternal Mortality}

\section{Linked to the modality of childbirth}

Deaths due to haemorrhagic causes were higher in women who gave birth vaginally (59\%) than by caesarean section.

Table 10: Distribution of maternal deaths by risk of death due to delivery route

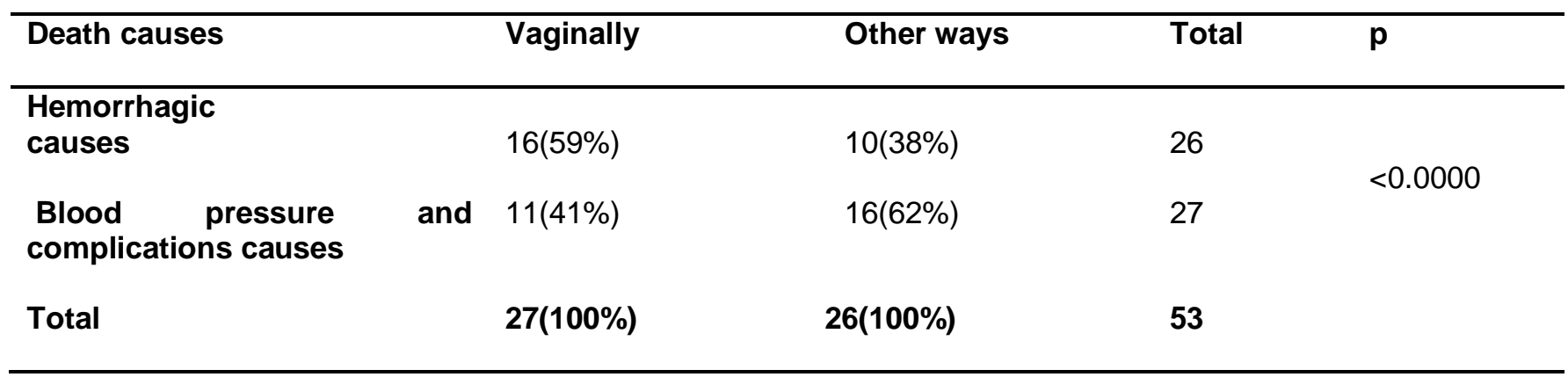

Factors linked to age, parity and number of ANC
In fact, mean parity (4.3) and mean number of ANCs (2.1) were higher in mothers who died of 
haemorrhage ( $p<0.05$ ); while for age no The analysis showed that maternal age association was observed. influenced fetal prognosis. This association was

Prognostic factors for children

Age-related factors, parity and number of prenatal consultations statistically significant and confirmed by a $p=$ 0.0382 . Parity and number of ANCs had no influence on the fate of the child with $p=0.2350$ and $p=0.0835$ respectively (Table 11 ).

Table 11: Distribution of maternal deaths by age, parity, number of ANCs and cause of death

\begin{tabular}{lllll}
\hline Causes of death & Number & & Mean & p \\
\hline Age $\quad$ Hemorrhagies & 40 & 26.3 & \\
& HBP and complications & 41 & 28 & 0.7184 \\
Parity & Hemorrhagies & 40 & 4 & \\
$\quad$ HBP and complications & 41 & 4.3 & 0.0420 \\
$\quad$ Hemorrhagies & 76 & 2,1 & \\
$\begin{array}{l}\text { Number } \\
\text { ANC HBP and complications }\end{array}$ & 75 & 1.8 & 0.0216 \\
\hline
\end{tabular}

Table 11: Distribution of maternal deaths by cause of death and fate of children.

\begin{tabular}{llll}
\hline Parameters & Number & & Mean \\
\hline $\begin{array}{c}\text { Causes of death } \\
\text { Living children }\end{array}$ & 72 & 26.4 & \\
Age $\quad$ Dead children & 48 & 29.8 & 0.0382 \\
Living children & 72 & 4,1 & \\
Parity $\quad \begin{array}{l}\text { Dead children } \\
\text { Living children }\end{array}$ & 48 & 3 & 0.2350 \\
$\begin{array}{c}\text { Number of ANC } \\
\text { dead }\end{array}$ & 31 & 1.7 & \\
\hline
\end{tabular}

\section{Related to the delivery route}

Of the children born vaginally, $46.1 \%$ were alive compared to $48.2 \%$ among those who were born by caesarean. The correlation was statistically significant with $p=0.0435$ (Table 12).

Table 12: Distribution of children's prognosis according to the delivery route.

\begin{tabular}{lllll}
\hline Parameters & vaginally & Other ways & Total & $\mathbf{p}$ \\
\hline Living children & $12(46.1 \%)$ & $27(48.2 \%)$ & 39 & \\
& & & & \\
Dead children & $14(53.9 \%)$ & $29(51.8 \%)$ & 43 & \\
Total & $\mathbf{2 6}$ & $\mathbf{5 6}$ & $\mathbf{8 2}$ & \\
\hline
\end{tabular}




\section{Discussion}

\section{Epidemiology}

\section{Incidence of maternal mortality}

In our series, from 2012 to 2016 at Kolda Regional Hospital Center, the maternal mortality rate was 2915.4 per 100,000 live births. This rate would be more than ten times the national average (315 per 100,000 NV in 2015)[3.4].
However, this is an intra-hospital rate. The national rate is an estimate of maternal mortality as a proportion of population.

Our result was closer to that found by Saizonou [5] in Benin where the intra-hospital maternal mortality rate at the Zou-Collines hospital center was 4769 per 100,000 live births (Table 13).

Table 13: Maternal Mortality Ratio by Country

\begin{tabular}{llll}
\hline Survey & Country & Year & Maternal Mortality Ratio \\
\hline Formulu [6] & Cameroun & 2006 & $365 / 100000$ LB \\
Saizonou [5] & Benin & 2006 & $4769 / 100000$ LB \\
Saucedo [7] & France & 2010 & $9.6 / 100000$ LB \\
Thiam [8] & Sénégal & 2010 & $615.8 / 100000$ LB \\
Mayi-Tsonga [9] & Gabon & 2010 & $270 / 100000$ LB \\
Our survey & Sénégal & 2016 & $2915.4 / 100000$ LB \\
\hline
\end{tabular}

LB: living birth

However, in developed countries the maternal ratio is much lower, notably in France 9.6 per 100,000 live births, in the United Kingdom 11.4 per 100,000 live births and in Finland 5.7 per 100,000 live births $[1,7]$.

\section{Socio-demographic characteristics}

\section{Age}

The most affected age group was 25-34 years old with $60 \%$. The young age found in our series is classic. The average age was 27 years old with extremes of 16 and 40 years. Age was not a risk factor for maternal mortality $(p=0.7184)$ but had an influence on fetal prognosis $(p=$ 0.0382 ). These results are comparable to those found in Gabon by Mayi-Tsonga [11] where the average age was 25 years with extremes of 16 and 41 years. Similarly, in Cameroon, Foumane [12] found a higher incidence of maternal mortality for the 25-34 age group. In Madagascar, the average age was higher with 31 years with extremes of 15 and 63 years [13]. The incidence of maternal mortality was low among women aged 35 and over with a frequency of $13 \%$. These contrasts with the results of Formulu et al [6], which states that women aged 40 and over are 3 to 4 times more likely to experience maternal mortality than women under 20 years of age. Similarly, Saucedo [7] showed that in France, women over 45 years of age had a mortality eight times higher than those aged 25 and under.

\section{Parity}

In our series, pauciparous and multiparous were the most affected with respectively $32.5 \%$ and $50 \%$. However, there is a decrease in the incidence of maternal mortality to $8.2 \%$ in nulliparas. Our results are close to those of MayiTsonga [9] which asserted the frequency of maternal mortality was higher among the pauciparas $46 \%$ and multiparas $20 \%$. Similarly, Thiam [8] demonstrated to Baudouin that multipares were the most affected with an incidence of $48 \%$.

These results are contrary to those found by Formulu [6] where the ratio of maternal mortality was higher among nulliparas with 841 per 100,000 live births than among large multiparas with 600 per 100,000 live births. 


\section{Marital status}

In our study, the majority of deceased women were married with a rate of $99 \%$ against $1 \%$ of single women. This is due to the frequency of early marriages in our country especially in the Kolda region. It was the same in Thiam's study [8], which found $60.4 \%$ of married women and $1.9 \%$ of unmarried women.

Unlike certain authors, Foumane [12] in Cameroon and Mayi-Tsonga [9] in Gabon, found respectively $65.5 \%$ and $75 \%$ of single unmarried patients, which he explained by the high frequency of clandestine induced abortions and the lack of prenatal care.

\section{Clinical data}

\section{Prenatal consultations}

For good monitoring of pregnancy, WHO recommends at least four prenatal consultations $[1,2]$. In our series, we found that $91.2 \%$ of the deceased women had less than four ANCs, including $23.5 \%$ who had no ANC. Our results were similar to those of Cisse [14] who stated that $91 \%$ of the dead women had less than 4 ANCs, $30 \%$ of which had not received any prenatal care.

Our results were more important than those of Formulu et al. [6] in Yaoundé who stated that $66.6 \%$ of deaths were recorded in patients who had less than 04 prenatal consultations with $28.2 \%$ of female deaths who had not done any prenatal consultation. It was the same in the Thiam study [8] which concluded that $75 \%$ of women had less than 4 ANCs, $13.6 \%$ of whom had never made prenatal visits.

Several authors agree that high quality antenatal care reduces the rate of women dying during pregnancy and childbirth $[6,15]$. $[6,15,16]$.

\section{Admission data}

\section{Admission mode}

In our series, $84 \%$ of the patients were evacuated into or referred to our service. These results are similar to those of formulu [6] in Cameroon who found that the majority of the patients in her study were referred to / evacuated, that is $82.05 \%$ of cases.

Our results were superior to those of MayiTsonga [11], and Rafanomezantsoa [13] who found a lower incidence of evacuation respectively $17 \%$ and $46 \%$.

Thiam [8] in his series found that more than $50 \%$ of women were evacuated. These same findings have been reported by the studies conducted by Dumont [17]. The same observation was made at the UHC of Trecheville [18] for it is a subregional reference center; moreover patients are admitted there under bad conditions.

\section{Evacuation reasons}

In our work, preeclampsia / eclampsia, prolonged labor / dystocia and postpartum haemorrhage were the most important reasons for evacuation with $35.8 \%, 18.8 \%$ and $10.9 \%$, respectively. These results were different from those of Chelli [19] who showed that haemorrhages were the first reason for evacuation with $27 \%$. Similarly for Thiam [20], hemorrhages were the first reason for evacuation with $42.4 \%$ followed by preeclampsia / eclampsia $11.5 \%$ and dystocia $10.3 \%$.

\section{Transportation Means}

Seventy-nine percent of the patients were evacuated with unequipped ambulance. Contrary to Thiam [8], only $18.8 \%$ of patients were evacuated by ambulance. These same figures were found in the series of Aboubakary [21] at KARA CHU where only $13.8 \%$ of patients were evacuated in equipped ambulance.

\section{Mode of delivery}

In our series, $39 \%$ of patients had a cesarean section. The caesarean section death rate was $3.74 \%$. Diallo et al [22] in Guinea and Pabamé [23] in N'Djamena, each reports a case fatality rate of $3.4 \%$. In his study, Bouillin [24] found a caesarean section death rate of $4.4 \%$ in Senegal with regional disparities ranging from $1.3 \%$ in Dakar to $11.5 \%$ in Kolda. A much lower rate is recorded in Burkina Faso [10], ie 2.3\%. These rates are certainly not comparable with those in 
developed countries where caesarean lethality varies between 0.07 and $0.34 \%[25,26]$.

\section{Fetal prognosis}

Neonatal mortality was $58.8 \%$ in our series and was mainly due to retroplacental hematoma, arterial hypertension and its complications as well as uterine rupture. This rate remains higher than the rate of $23 \%$ found by Cissé [27] in Le Dantec, and the rate of $18 \%$ found by Thiam [8] in Dioum.

\section{Etiological data}

\section{Causes of death}

In our study the direct causes, which are postpartum hemorrhages and high blood pressure and its complications accounted for $68 \%$ of cases.

Our results were higher than those of other studies, specially than those of Rafanomezantsoa in Madagascar [13] with $60 \%$, those of Cissé in Senegal [27] with 64\% and those of Saucedo in France [7] with 57.9\%.

Our rate is lower than that of Formulu [6] with $89.7 \%$ and Thiam [8] with $80 \%$.

Unlike Gabon, Mayi-Tsonga [9] demonstrated that the first indirect cause of maternal death was HIV / AIDS.

Postpartum haemorrhage is the leading cause of maternal mortality before blood pressure and its complications with a rate of $43.3 \%$.

Our results were corroborated by the studies of Formulu [6] and Cisse [27] where postpartum haemorrhage was the leading cause of maternal death with $56.4 \%$ and $30 \%$, respectively. Similarly, in a study conducted in Senegal, in a rural area, the causes of maternal deaths identified were, in order of frequency: postpartum haemorrhage, eclampsia, obstructed labor and puerperal infections [29]. In Mali, Kire [30] and Malle [31] found respectively $63.2 \%$ and $28.57 \%$ for haemorrhage and as the leading cause of death.

Our data were different from those of Rafanomezantsoa [13] in Madagascar and Foumane [12] in Cameroon, who stated that in their series, high blood pressure was the leading cause of maternal mortality. Similarly, the prevalence of hypertension during pregnancy was confirmed by several African studies including a multicentre study conducted in Benin, Ivory Coast and Senegal in which $29 \%$ of maternal deaths are due to high blood pressure. [32]. Similarly, toxemia during pregnancy is recognized as the leading cause of maternal mortality in Latin America and the Caribbean [33].

However, for Formulu [6], preeclampsia / eclampsia was the third leading cause of maternal mortality at $15.4 \%$. Similarly, at the UHC le Dantec, Cisse [27] found a maternal mortality by eclampsia of $20.6 \%$ while Tchaou [34] said that maternal mortality in Benin due to high blood pressure and its complications was 6 , $8 \%$.

Another study in Guinea, between 1997 and 1999, recorded 12 maternal deaths out of 226 cases of hypertension, a death rate of 5.3 [35]. Akpadza and his collaborators in Togo report $2.82 \%$ [36]. Toure and his collaborators in Niger report 2.8\% [37]. A Malagasy study at the Soavinandriana Hospital Center in 2005-2008 indicated that there were no maternal deaths related to arterial hypertension and its complications in a series of 77 cases, which implies a speed and effectiveness of management [29].

In Ghana, infections were the leading cause of maternal mortality from 2008 to 2010 with $19.4 \%$ of cases [38]. From 2000 to 2002, Benhamou et al found that infections accounted for 12 cases out of 261 maternal deaths in the United Kingdom and 7 cases out of 222 maternal deaths in France [39].

\section{Moment of death}

Most of our women died in the first 48 hours of postpartum, $79 \%$. These figures are similar to those found in Mali in 2008, with $70 \%$ of maternal deaths in the first two days postpartum [60]. Similarly Thiam [8] found in his series that $76 \%$ of deaths occurred in the postpartum. 
Contrary to our results, Mayi-Tsonga [9] claimed that only $7 \%$ of deaths occurred in the post partum and $93 \%$ of deaths in per partum.

\section{Conclusion of maternal death audits}

Our study reveals that:

- The delay in the consultation was the cause of death in $52 \%$ of the cases; either because they resort to health centers late; or because they refuse to receive care

- The delay in evacuation by late transfer of the patient was evoked in $25 \%$ of deaths;

- delay to treatment due to staff shortages or administration default: either by misdiagnosis, inappropriate treatment, lack of supervision, or shortage of essential drugs or blood products or by non-availability of the operation ward was found in $23 \%$ of maternal deaths.

According to the audit committee, $70 \%$ of the deaths among the audited files were avoidable. These deaths are usually related to a lack of blood products, financial difficulties or unavailability of emergency medications.

Deaths were preventable in $60 \%$ of anemia cases , $47.3 \%$ of hemorrhages cases and $40 \%$ of infections. The haemorrhagic group has the largest share of preventable deaths, $84 \%$; followed by high blood pressure complications and infections $62 \%$ and $57 \%$, respectively [7].

In Adis Abeba, the use of maternal death audits has determined that $67 \%$ of avoidance factors are related to the competence of medical staff and lack of blood [39].

\section{Conclusion}

The maternal mortality rate in Senegal is no exception to the rule as in all developing countries. The region of Kolda is one of the most affected one in Senegal. Such a phenomenon can be attributed to several factors, late evacuations linked to a lack of means of communication and transportation, and financial constraints, which delay the implementation of emergency obstetric care. Strategic interventions to reduce this mortality rate should be based on community education on safe motherhood, on raising the standard of living of the population, on improving the level of education, communication systems and better transportation, access to quality reproductive health services and availability of emergency obstetric care.

\section{References}

1. WHO. Global Strategy for Women's, Children's and Adolescents' Health (2016-2030) Every woman, every child, UN, 2015.

2. Say L, Chou D, Gemmill A, Tunçalp Ö, Moller AB, Daniels JD, et al. Global Causes of Maternal Death: A WHO Systematic Analysis Lancet Global Health. 2014;2(6): e323-e333.

3. National Agency for Statistics and Demography of Senegal: Maternal mortality 2105.

4. WHO MSAS, UNFPA, UNICEF, CEFOREP Evaluation of Obstetric and Neonatal Emergency Care in Senegal 2012-2013, Dakar 2014; 30-50.

5. Saizonou J, Ouendo E M, Dujardin B. Deaths audit in four Benin Referral Hospitals: Quality of Emergency Care, Causes and Contributing Factors. Afr. J. Reprod. Health 2006; Vol. 10, n³ : 170-176.

6. Fomulu $\mathrm{J} N$, Ngassa $P \mathrm{~N}$, Nong $T$, Nana $P$, Nkwabong E. Maternal Mortality at the Maternity Hospital of the Yaoundé University and Hospital Center, Cameroon: A 5-Year Retrospective Study (2002 to 2006) .Health Sci. Dis. 2009; Vol 10 (1): 22-27.

7. Saucedo M, Deneux-Tharaux C, Bouvier-Colle $\mathrm{M} \mathrm{H}$. Epidemiology of maternal mortality in France, 2007-2009. J. Gynecol. Obstet. Biol. Reprod. 2013; 42: 613-27.

8. Thiam O, Cissé M L, Mbaye M, Niang M M, Gueye $M$, Diouf A A, Dièye S, Moreau J C . The issue of parturients evacuated in Senegalese rural area: example of the Ndioum Hospital Center. Rev. CAMES Health 2013; Vol.1, No. 2: 51-56.

9. Mayi-Tsonga $S$, Oksana L, Diallo T, Metogho M, Ndombi I, Mendome G, Mounanga M, Meye J F. Study on maternal deaths at the Hospital Center of Libreville. Med. Afr. Black 2010; No. 5709: 425431.

10. Ouédraogo $\mathrm{C}$, Bouvier-Colle $\mathrm{M} \mathrm{H}$. Maternal Mortality in West Africa: How, How and Why? J. Gynecol. Obstet. Biol. Reprod. 2002; 31: 80-89.

11. Mayi-Tsonga S, Ndombi I, Oksana I,Methogo M, Diallo T, Mendome G, Mounanga M. Maternal mortality in Libreville (Gabon): state of play and challenges to be met in 2006. Cahiers Santé 2008; flight. 18, No. 4: 193-197. 
12. Foumane $P$, Dohbit J S, Ngo Um Meka E, Nkada M N, Ze Minkande J, Mboudou E T. Etiologies of Maternal Mortality at the Gyneco-Obstetrics and Pediatric Hospital of Yaounde: a series of 58 deaths. Health Sci. Dis. 2015 ; Vol 16 (3): 32-36.

13. Rafanomezantsoa $T$ A, Harioly Nirina $M O J$, Fenomanana S, Ramarokoto $M \quad P M$, Andrianampanalinarivo $\mathrm{H} \mathrm{R}$, Raveloson $\mathrm{N}$. Maternal Mortalities seen at the University Hospital of Gynecology-Obstetrics of Befelatanana: 2011-2013. Med. Afr. Black 2014; No. 6112: 622-628.

14. Cissé ML, Raad B, Diouf A, Wade F, Moreau J C. Assessment of obstetric evacuation at the Kolda Regional Hospital. Med. Afr. Black 2010; Flight. 57, No. 1: 37-43.

15. WHO. The World Health Report 2005. Make every mother and child count, Genève, 2005,10-15.

16. Bouvier-Colle $M H$, Mohangoo $A D$, Gissler $M$, Novak-Antolic Z, Vutuc C, Szamotulska K et al. What about the mothers? An analysis of maternal mortality and morbidity in perinatal health surveillance systems in Europe.BJOG 2012; 119:889-90.

17. Dumont A, De Bernis L, Boulin D. Maternal morbidity and qualification of health personnel: comparison of two different populations in Senegal. J. Gynecol. Obstet. Biol. Reprod. 2002; 31: 70-79.

18. N'guessan E, Bouhoussou P E, Toure B, Djanhan L, Tegnan J A, Guie P A, Anongba S, Toure Coulibaly K. Risk Factors for Maternal Mortality in Adolescent Girls. About 60 cases collected at the Gynecology and Obstetrics Department of the University Hospital of Treichville.

19. Med. Afr. Noire 2010; No. 571: 521-526.

20. Chelli D, Dimassi K, Zouaoui B, Sfar E, Chelli $\mathrm{H}$, Chennoufi M B. Evolution of maternal mortality in a Tunisian maternity level 3 between 1998 and 2007. J. Gynecol. Obstet. Biol. Reprod. 2009; 38: 655-61.

21. Thiam O, Cissé M L, Niang M M, Gaye A, Diouf A, Moreau J C. Maternal mortality at Roi Baudouin Health Center: about 308 cases. Mali Medical 2014; Volume XXIX, No. 3 pages 17-21.

22. Aboubakary A S. Maternal mortality at Kara University Hospital: incidence, causes and risk factors. J. of SAGO 2006; 7, (1) 21-25.

23. Diallo F B, Diallo M S, Bangoura S, Diallo A B, Camara Y. Cesarean section: Fetal and maternal mortality reduction factor at the Ignace Deen University Hospital in Conakry (Guinea). Med. Afr. Noire 1998; 45 (6): 359-364.

24. Pabamé $Z$ et al. Quality of Caesarean section in N'Djamena health reference structures: analysis of the determinants of 235 cases.Thesis Med. N'Djamena 2002; n45: 108p.

25. Bouillin D, Fournier G, Gueye A, Diadhiou F, Cissé C T. Epidemiological surveillance and surgical coverage of obstetric dystocia in Senegal. Cahiers de Santé 1994; 4 (6): 399-406.

26. Philibert M. Epidemiology of maternal mortality in France from 1996 to 2002: frequency, risk factors and causes. BEH 2006; 50: 392-5.

27. Berg C, Bullough G, Fêtard J-F, Filippi V, Grahan $W$, Lewis $G$ et al.

Beyond Numbers: Examine maternal deaths and complications to reduce the risks of pregnancy. WHO, Geneva 2004.

28. Cissé M L, Moreau J C, Faye E H O, Cissé L, Terolbe I, Diadhiou F. Cost of the evacuation of parturients to the University Hospital Center Aristide Le Dantec of Dakar. J. SAGO 2002; 1.1: 23-27.

29. Chalumeau $M_{-}$Identification of risk factors for perinatal mortality in West Africa: prenatal consultation or childbirth surveillance: MMIA (Maternal Mortality in Africa). J. Gynecol. Obstet. Biol. Reprod. 2002, vol. 31, No.1: 63-69.

30. Randriambololona D M A. Evaluation of the risk factors and the maternal-fetal prognosis in the case of association high blood pressure and pregnancy at the Cenhosoa Maternity Hospital. Memory for obtaining the Diploma of Studies of Specialized Training (DEFS) in GynecologyObstetrics 2009; Madagascar, No. 166: 25-6.

31. Kiré B. Audit of maternal deaths at the reference center of Commune I of Bamako District. Thesis of Med. 2008; Bamako, no. 442: 70-80.

32. Mallé D, Ross D A, Campbell O M R. , Huttly S R A. Institutional maternal mortality in Mali. Int. J. Gynécol. Obstet.1994; 46:19-26.

33. Thonneau P F, Matsudai T, Alihonou E, De Souza $\mathrm{J}$, Faya O, Moreau J C et al.Distribution of causes of maternal mortality during delivery and postpartum: results of an African multicentre hospitalbased study. Eur. J. Obstét. Gynécol. Reprod. Biol. 2004; 114(2): 150-4.

34. Khan K S, Wojdyla D, Say L, Gülmezoglu AM, Van Look P F. WHO analysis of causes of maternal death: a systematic review. Lancet 2006 ; 367(9516):1066-74.

35. Tchaou B A, Hounkponou M F N, Salifou K, Zoumenou E, Chobli M. Obstetric emergencies at the University Hospital of Parakou in Benin: clinical, therapeutic and evolutionary aspects. Eur. Scientific J. 2015; vol.11, no.9: 260-72. 
36. Bah A O, Diallo M H, Conde A M, Keita N. High blood pressure and pregnancy: maternal and perinatal mortality. Med. Afr. Black 2001; 48: 4613.

37. Akpadza K, Beata S, Kotor K, Hodonou A K S.

Eclampsia at the Gynecology-Obstetrics Clinic of Tokoin-Lomé University Hospital (Togo). Med. Afr. Black 1996; 43: 166-9.

38. Toure I A, Bra H, Prual A. High blood pressure and pregnancy in Niger: Case-control study of 70 cases. Med. Afr. Black 1997; 205 -8.

39. WHO. Trend in maternal mortality from 19902015. WHO, Geneva, 2015; 2-12.

40. Benhamou D, Chassard F, Mercier J, BouvierColle M H. The 2003-2005 report on maternal mortality in the United Kingdom: comments and comparison with the French data. Ann. Anesth. Rea. 2009; 28: 38-43. 